\title{
The cluster-randomized Quality Initiative in Rectal Cancer trial: evaluating a quality-improvement strategy in surgery
}

\author{
Marko Simunovic MD, Angela Coates MEd, Charles H. Goldsmith PhD, Lehana Thabane PhD, \\ Dana Reeson MSc, Andrew Smith MD, Robin S. McLeod MD, Franco DeNardi MD, \\ Timothy J. Whelan MD, Mark N. Levine MD
}

Previously published at www.cmaj.ca

See also research article by Telford and colleagues, page 1307, and commentary by Smith, page 1283

\section{ABSTRACT}

Background: Following surgery for rectal cancer, two unfortunate outcomes for patients are permanent colostomy and local recurrence of cancer. We tested whether a qualityimprovement strategy to change surgical practice would improve these outcomes.

Methods: Sixteen hospitals were cluster-randomized to the intervention (Quality Initiative in Rectal Cancer strategy) or control (normal practice) arm. Consecutive patients with primary rectal cancer were accrued from May 2002 to December 2004. Surgeons at hospitals in the intervention arm could voluntarily participate by attending workshops, using opinion leaders, inviting a study team surgeon to demonstrate optimal techniques of total mesorectal excision, completing postoperative questionnaires, and receiving audits and feedback. Main outcome measures were hospital rates of permanent colostomy and local recurrence of cancer.

Results: A total of 56 surgeons ( $n=558$ patients) participated in the intervention arm and 49 surgeons ( $n=457$ patients) in the control arm. The median follow-up of patients was 3.6 years. In the intervention arm, $70 \%$ of surgeons participated in workshops, $70 \%$ in intraoperative demonstrations and $71 \%$ in postoperative questionnaires. Surgeons who had an intraoperative demonstration provided care to $86 \%$ of the patients in the intervention arm. The rates of permanent colostomy were $39 \%$ in the intervention arm and $41 \%$ in the control arm (odds ratio [OR] $0.97,95 \%$ confidence interval $[\mathrm{Cl}] 0.63-1.48)$. The rates of local recurrence were $7 \%$ in the intervention arm and $6 \%$ in the control arm (OR 1.06, 95\% Cl 0.68-1.64).

Interpretation: Despite good participation by surgeons, the resource-intense quality-improvement strategy did not reduce hospital rates of permanent colostomy or local recurrence compared with usual practice. (ClinicalTrials.gov trial register no. NCT00182130.)

$\mathrm{F}$ ollowing surgery for rectal cancer, two unfortunate outcomes for patients are permanent colostomy and local recurrence of the cancer. Local recurrence is especially feared, because it is usually inoperable and patients can suffer a slow, painful death. ${ }^{1}$ The use of total mesorectal excision, which involves dissection of the lymph node-bearing portion of the rectum, ${ }^{2}$ has resulted in improved outcomes, with local recurrence rates as low as $1 \%-5 \%$ and rates of permanent colostomy of $10 \%-15 \% .^{3-6}$ Population-based rates of local recurrence are unavailable for any North American jurisdiction, although a Canadian hospital series found that rates varied from $10 \%$ to $45 \%$ based on the practice volume and training of surgeons. ${ }^{7}$ A surgical report on health regions in the province of Ontario (population 13 million) found that rates of permanent colostomy varied from $31 \%$ to $41 \%{ }^{8}$ This geographic variation in outcomes, together with rates of inferior outcomes as compared to outcomes specific to total mesorectal excision, suggest that gaps exist in the quality of rectal surgery provided to patients with rectal cancer.

Quality-improvement strategies for encouraging physicians to change practice include continuing medical education, the use of opinion leaders, and audit and feedback. ${ }^{9-11}$ As well, improvement may be enhanced by using a participatory and supportive approach that focuses on the system and not on individual practitioners. ${ }^{12,13}$ The small number of studies that have evaluated changes in surgeons' practices often have targeted process measures, such as preoperative ordering of antibiotics, rather than patient outcomes, such as recurrence of cancer..$^{14,15}$

We tested whether use of a surgeon-directed quality-improvement strategy would improve hospital rates of permanent colostomy and local recurrence of cancer among patients undergoing surgery for rectal cancer. We used the Quality Initiative in Rectal Cancer (QIRC) strategy, which integrates qualityimprovement interventions and principles to encourage surgeons to provide optimal total mesorectal excision to patients with rectal cancer. ${ }^{16}$

From the Department of Surgery (Simunovic, Coates, Reeson), McMaster University, St. Joseph's Healthcare, Hamilton, Ont.; the Department of Clinical Epidemiology and Biostatistics, Faculty of Health Sciences (Simunovic, Goldsmith, Thabane, Whelan, Levine), McMaster University, Hamilton, Ont.; the Juravinski Cancer Centre (Simunovic, Whelan, Levine), Hamilton, Ont.; the Biostatistics Unit, St. Joseph's Healthcare (Goldsmith, Thabane), Hamilton, Ont.; the Division of General Surgery (Smith), University of Toronto, Sunnybrook Health Sciences Centre, Toronto, Ont.; the Departments of Surgery and of Health Policy Management and Evaluation, University of Toronto, and the Department of Surgery, Samuel Lunenfeld Research Institute, Mount Sinai Hospital (McLeod), Toronto, Ont.; the Department of Pathology and Molecular Medicine (DeNardi), McMaster University, Henderson General Hospital, Hamilton, Ont.; and the Department of Oncology, Faculty of Health Sciences (Whelan, Levine), McMaster University, Hamilton, Ont.

CMAJ 2010. DOI:10.1503/cmaj.091883 


\section{Methods}

\section{Participants}

\section{Hospitals}

The protocol for this cluster-randomized trial at the hospital level has been described previously. ${ }^{17} \mathrm{We}$ selected hospitals in the province of Ontario with an annual volume of 15 or more major resections for rectal cancer. We identified 33 such hospitals using administrative data from Apr. 1, 2000, to Mar. 31, 2001. Sample-size calculations indicated the need for 16 sites. Hospitals were eligible if at least $60 \%$ of the surgeons at the hospital agreed to participate in the trial and the hospital's research ethics board approved the study. For the first 18 hospitals approached, nearly all surgeons consented to participate and the research ethics boards at 16 hospitals approved the study (Figure 1). At the two other hospitals, the research ethics board required individual patient consent, a provision that countered the methodologic requirement for consecutive accrual of patients. ${ }^{17}$ Because hospitals were our unit of analysis, consecutive patients had to be included to prevent potential selection bias by surgeons (e.g., excluding patients with difficult tumours perceived to be at high-risk of negative outcomes). This precluded approaching patients for consent or data on the main outcomes.

\section{Patients}

Patients were eligible if they underwent major rectal surgery (i.e., partial or complete segmental resection of the rectum with or without an anastamosis) because of a diagnosis of primary rectal cancer. We defined rectal cancer as a tumour within 15 $\mathrm{cm}$ of the anal verge located by means of rigid sigmoidoscopy, or a tumour at or below the level of the sacral promontory seen during surgery. This ensured the inclusion of patients who would potentially benefit from total mesorectal excision.

\section{Intervention}

The QIRC strategy consisted of five surgeon-directed components: workshops, the use of opinion leaders, intraoperative demonstrations, postoperative questionnaires, and audit and feedback. Workshops preceded other interventions at participating hospitals. Workshop topics included techniques of total mesorectal excision and quality improvement. At each workshop, participating surgeons selected an opinion leader for their hospital using a validated approach. ${ }^{18}$ The opinion leader acted as a local resource person on issues pertinent to the study. For intraoperative demonstrations, participating surgeons invited a study team surgeon to assist them with a patient's rectal cancer surgery. The intent was for the invited surgeon to demonstrate optimal techniques of total mesorectal excision. Demonstrators were recognized experts in total mesorectal excision, although participating surgeons retained full control over decision-making. A postoperative questionnaire was designed to prompt surgeons to re-examine key steps in total mesorectal excision. For audit and feedback, data (e.g., rates of permanent colostomy) were provided to individual surgeons for their own results and those of their hospital.

Participating surgeons at hospitals in the control arm received no interventions. The onus was on individual surgeons to obtain new knowledge or skills for any aspect of care they provided.

\section{Outcome measures}

The two main outcome measures were hospital rates of permanent colostomy and local recurrence of cancer.

It is usually known at the time of surgery whether a person has received a permanent colostomy. However, when patients received a potentially temporary stoma, 12 months was allowed for stoma closure. An anastomosis of the rectum had to be functioning for three months to be considered a nonpermanent colostomy.

Local recurrence of cancer was defined as a tumour that recurred in the pelvis. ${ }^{1,17}$ Most, although not all, local recurrences manifest within two years after surgery. ${ }^{1}$ We thus followed all patients in the trial for at least 30 months.

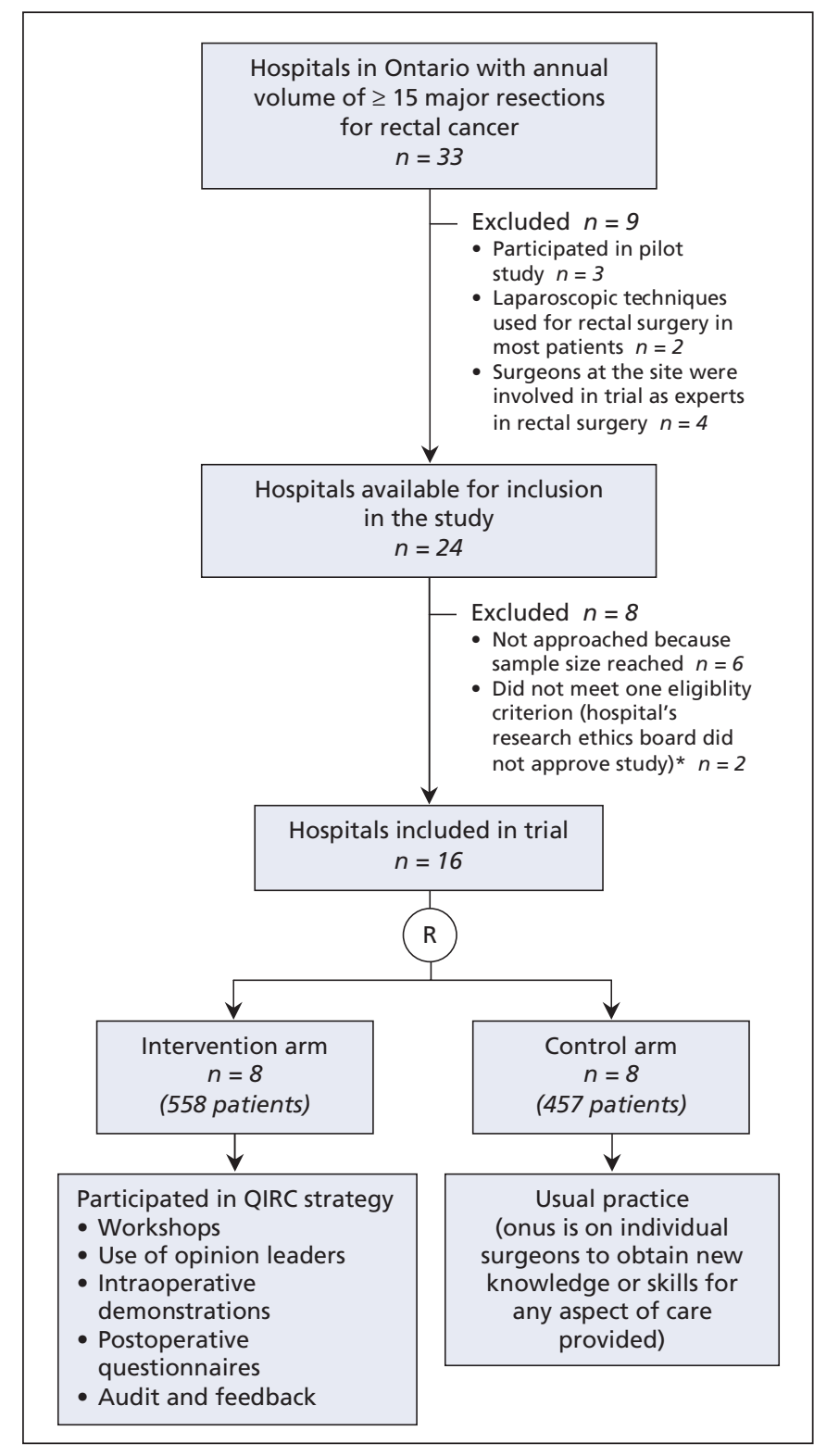

Figure 1: Selection of hospitals for cluster-randomized trial of the Quality Initiative in Rectal Cancer (QIRC) strategy to improve outcomes of patients undergoing major resection for rectal cancer. *Eligibility criteria: $\geq 60 \%$ of surgeons at the hospital consented to participate, and the hospital's research ethics board approved the study. $\mathrm{R}=$ randomization. 


\section{Sample size}

We calculated the intraclass correlation coefficient for permanent colostomy using administrative data for Ontario hospitals for the years 1997 to 1999 (intracluster correlation $=0.04$ ). ${ }^{19} \mathrm{~A}$ conservative spectrum of intraclass correlation coefficients were used for local recurrence of cancer. Coefficients were integrated into the sample-size calculations. ${ }^{19}$ Alpha was set at 0.05 , and $\beta$ was set at 0.2 . We assumed a clinically important change would consist of a decrease in the baseline rate of permanent colostomy from $30 \%$ to $15 \%$. For local recurrence, we assumed rates would decrease from a conservative estimate of $20 \%$ to $8 \%$. This latter change drove our sample-size requirements. To detect this difference with confidence, a minimum of eight hospitals and 336 patients in each study arm were required.

\section{Randomization}

Because surgeons in Ontario rarely perform surgery for rectal cancer at more than one hospital, we used a cluster-randomized design at the hospital level to minimize the chances of contamination among surgeons and patients in the control arm. A study statistician (C.H.G.) generated and administered a blocked 1:1 allocation arrangement for randomization of the 16 study hospitals. Surgeons were not blinded to group assignment, since those in the intervention group had to actively engage in the QIRC strategy.

\section{Data collection}

Methods for accrual of patients included telephone calls to surgeons' offices, review of booking logs for operating rooms and review of hospital health records. Data were collected using standard forms. Hospital charts were reviewed within two weeks after surgery and every three months thereafter. Charts from regional cancer centres in the province were reviewed to optimize the collection of data on adjuvant treatments (e.g., radiation therapy and chemotherapy) and study outcomes. In Ontario, all radiation therapy and most chemotherapy is delivered at a small number of regional cancer centres. Data were collected for at least 30 months.

\section{Statistical analysis}

All analyses were done on an intention-to-treat basis. We compared study arms with respect to potential covariates using descriptive statistics. These included patient characteristics (age, sex and comorbidities), tumour-related variables (size, tumour-nodes-metastisis [TNM] stage, presence of lymphatic vascular or neural invasion, grade, height of tumour from anal verge, and radial margin status) and treatment-related variables (use of radiation or chemotherapy). For local recurrence, analyses also included type of final procedure (low anterior resection or permanent colostomy).

Methods of analyses included consideration of the clusterrandomization trial design, adjustment for covariates and multiple imputation to handle missing data. ${ }^{19,20}$ We used generalized estimating equations (GEE) assuming an exchangeable correlation structure to assess the treatment effect on permanent colostomy. ${ }^{21}$ For time to local recurrence, we used survival analysis techniques for clustered data based on the sandwich (covariance matrix) estimator. ${ }^{22}$ If a study event was not identified for a patient, they were assumed to be event-free at the time of study closure for the survival analyses. We did not include a chemotherapy covariate in our multivariable models because of marked correlation in the use of radiation therapy and chemotherapy. To assess the sensitivity of our inferences, all models were re-run without imputing missing values; the results remained robust. We also did an exploratory analysis of cases in the experimental arm that did and did not have an operative demonstrator in attendance. For all tests, we used an $\alpha$ value of 0.05 for the level of significance. The results are reported as odds ratios (ORs) or hazard ratios (HRs) with $95 \%$ confidence intervals (CIs).

Table 1: Baseline patient, tumour and process-of-care characteristics, by trial arm

\begin{tabular}{|c|c|c|}
\hline \multirow[b]{2}{*}{ Characteristic } & \multicolumn{2}{|c|}{ Trial arm; no. (\%) of patients* } \\
\hline & $\begin{array}{l}\text { Intervention } \\
\quad n=558\end{array}$ & $\begin{array}{l}\text { Control } \\
n=457\end{array}$ \\
\hline Hospitals, no. (\%) & $8(50.0)$ & $8(50.0)$ \\
\hline Surgeons, no. (\%) & $56(53.3)$ & 49 (46.7) \\
\hline \multicolumn{3}{|l|}{ Patient } \\
\hline Age, yr, median (IQR) & $69.0(60.0-77.0)$ & $68.0(60.0-76.0)$ \\
\hline Sex, male & $339(60.8)$ & $293(64.1)$ \\
\hline \multicolumn{3}{|l|}{ Comorbidities } \\
\hline 0 & $410(73.5)$ & $346(75.7)$ \\
\hline 1 & $114(20.4)$ & $91(19.9)$ \\
\hline$\geq 2$ & $34(6.1)$ & $20(4.4)$ \\
\hline \multicolumn{3}{|l|}{ Tumour } \\
\hline Size, cm, median (IQR) & $4.0(3.0-5.0)$ & $4.0(3.0-5.0)$ \\
\hline \multicolumn{3}{|l|}{ TNM stage } \\
\hline 1 & $134(24.0)$ & $121(26.5)$ \\
\hline 2 & $128(22.9)$ & $121(26.5)$ \\
\hline 3 & $205(36.7)$ & $125(27.4)$ \\
\hline 4 & $59(10.6)$ & $53(11.6)$ \\
\hline Unable to stage & $32(5.7)$ & $37(8.1)$ \\
\hline \multicolumn{3}{|l|}{ Histologic grade } \\
\hline Well differentiated & $50 \quad(9.0)$ & $37(8.1)$ \\
\hline Moderately differentiated & $432(77.4)$ & $318(69.6)$ \\
\hline Poorly differentiated & $32(5.7)$ & $50(10.9)$ \\
\hline Missing & $44(7.9)$ & $52(11.0)$ \\
\hline $\begin{array}{l}\text { Vascular, lymphatic or } \\
\text { neural invasion }\end{array}$ & $146(26.2)$ & $134(29.3)$ \\
\hline $\begin{array}{l}\text { Distance of tumour from } \\
\text { anal verge, } \mathrm{cm} \text {, median (IQR) }\end{array}$ & $10.0(5.0-13.0)$ & $10.0(5.0-15.0)$ \\
\hline \multicolumn{3}{|l|}{ Process of care } \\
\hline $\begin{array}{l}\text { No. of lymph nodes } \\
\text { examined, median (IQR) }\end{array}$ & $10(7.0-14.0)$ & $10(6.5-16.0)$ \\
\hline $\begin{array}{l}\text { Positive circumferential } \\
\text { radial margint }\end{array}$ & $41(7.3)$ & $44 \quad(9.6)$ \\
\hline Preoperative radiation & $87(15.6)$ & $43 \quad(9.4)$ \\
\hline Postoperative radiation & $107(19.2)$ & $89(19.5)$ \\
\hline Preoperative chemotherapy & $64(11.5)$ & $40 \quad(8.8)$ \\
\hline Postoperative chemotherapy & $201(36.0)$ & $159(34.8)$ \\
\hline
\end{tabular}

Note: IQR = interquartile range, TNM = tumour-nodes-metastasis.

*Unless stated otherwise.

tPositive circumferential radial margin $=$ distance $\leq 1 \mathrm{~mm}$ 


\section{Ethics}

The study was conducted according to appropriate ethics guidelines. ${ }^{23}$ The Research Ethics Board of Hamilton Health Sciences and the Faculty of Health Sciences, McMaster University, approved the study protocol, as did the research ethics boards at the participating hospitals and regional cancer centres.

\section{Results}

\section{Participants}

The trial involved 56 surgeons working at the eight hospitals in the intervention arm, and 49 surgeons at the eight hospitals in the control arm. We accrued 1015 patients (558 in the intervention arm and 457 in the control arm) from May 15, 2002, to Dec. 10, 2004 (Figure 1). Participation in the trial was high (96 [91\%] of the 105 surgeons), with five nonconsenting surgeons in the intervention arm and four in the control arm). We included both patients treated by consenting surgeons and those treated by nonconsenting surgeons.

At the intervention sites, $39(70 \%)$ of the 56 surgeons attended a workshop, 39 (70\%) participated in at least one intraoperative demonstration, and $40(71 \%)$ completed at least one postoperative questionnaire. Surgeons who took part in an operative demonstration provided care to $86 \%$ of the patients. Audit results and feedback were mailed to all consenting surgeons in the intervention arm.

Table 2: Rates and odds of permanent colostomy and local recurrence of cancer among patients, by trial arm

\begin{tabular}{|c|c|c|c|c|}
\hline \multirow[b]{2}{*}{ Outcome } & \multicolumn{2}{|c|}{ Trial arm; no. (\%) of patients } & \multirow[b]{2}{*}{$\mathrm{OR}^{*}(95 \% \mathrm{Cl})$} & \multirow{2}{*}{$\begin{array}{l}\text { Intra-class } \\
\text { correlation } \\
\text { coefficient }\end{array}$} \\
\hline & $\begin{array}{c}\text { Intervention } \\
n=558\end{array}$ & $\begin{array}{l}\text { Control } \\
n=457\end{array}$ & & \\
\hline \multicolumn{5}{|c|}{ Permanent colostomy } \\
\hline \multicolumn{5}{|l|}{$\begin{array}{l}\text { Procedure at } \\
\text { initial surgery }\end{array}$} \\
\hline $\begin{array}{l}\text { Permanent } \\
\text { colostomy }\end{array}$ & $146(26.2)$ & $132(28.9)$ & & \\
\hline $\begin{array}{l}\text { Hartmann's } \\
\text { resection }\end{array}$ & $20 \quad(3.6)$ & $27 \quad(5.9)$ & & \\
\hline $\begin{array}{l}\text { Low anterior } \\
\text { resection with } \\
\text { ileostomy }\end{array}$ & $101(18.1)$ & $46(10.1)$ & & \\
\hline $\begin{array}{l}\text { Low anterior } \\
\text { resection }\end{array}$ & $291(52.2)$ & $252(55.1)$ & & \\
\hline $\begin{array}{l}\text { Final procedure } \\
\text { - permanent } \\
\text { colostomy }\end{array}$ & $218(39.1)$ & $185(40.5)$ & $0.97(0.63-1.48)$ & 0.029 \\
\hline \multicolumn{5}{|l|}{ Local recurrence } \\
\hline Definitet & $20 \quad(3.6)$ & $20 \quad(4.4)$ & & \\
\hline Probable $\neq$ & $16 \quad(2.9)$ & $7 \quad(1.5)$ & & \\
\hline Possible§ & $0 \quad(0.0)$ & $2 \quad(0.4)$ & & \\
\hline Any & $36 \quad(6.5)$ & $29 \quad(6.4)$ & $1.06(0.68-1.64)$ & -0.003 \\
\hline
\end{tabular}

Note: $\mathrm{Cl}=$ confidence interval, $\mathrm{OR}=$ odds ratio.

* Generalized estimating equation (GEE) models considered clustering of data at hospital level.

tPositive histologic result from pelvic mass.

‡Pelvic mass with any sign (hydronephrosis, invasion of pelvic structures or bleeding) or symptom (deteriorating sexual, bladder or bowel function; or persistent or worsening lower back, perineal or sciatic pain).

§Any symptom of probable recurrence, as described above.
Charts from the study hospitals and regional cancer centres were reviewed to the end of 2007 for patients in both arms. Median follow-up of patients was 3.6 years. The two arms of the trial were evenly matched on most of the patient and tumour characteristics (Table 1).

\section{Permanent colostomy and local recurrence of cancer}

The rate of permanent colostomy was 39\% in the intervention arm and $41 \%$ in the control arm (OR 0.97, 95\% CI 0.63-1.48). The rate of local recurrence was $7 \%$ in the intervention arm and $6 \%$ in the control arm (OR 1.06, 95\% CI 0.68-1.64) (Table 2). A Kaplan-Meier curve of time to local recurrence is presented in Appendix 1 (available at www.cmaj.ca/cgi/content/full/cmaj $.091883 / \mathrm{DC} 1)$. There was no significant difference in time to local recurrence between the study arms.

In the multivariable analyses, the odds of a permanent colostomy did not differ significantly between the intervention and control arms (OR 0.70, 95\% CI 0.38-1.30) (Appendix 2, available at www.cmaj.ca/cgi/content/full/cmaj.091883/DC1). As expected, various factors increased the odds of a permanent colostomy, including male sex, older age, higher comorbidity score, the use of preoperative radiation, positive circumferential radial margin and closer distance to the anal verge. The hazard of local recurrence was not statistically different between the intervention and control arms (HR 0.96, 95\% CI 0.61-1.52) (Table 3). Results of the analyses were similar when missing data were not imputed, with the exception that use of preoperative radiation was no longer a risk factor for permanent colostomy.

In the intervention arm, the median distance of the tumour from the anal verge was $6 \mathrm{~cm}$ among patients whose surgeon had an intraoperative demonstration, as compared with $10 \mathrm{~cm}$ among those whose surgeon did not have an intraoperative demonstration $(p<0.001)$ (Appendix 3, available at www.cmaj.ca/cgi/content /full/cmaj.091883/DC1). Participating surgeons possibly invited operative demonstrators for patients whose tumour was closer to the anal verge and who thus were more likely to require a colostomy. Nevertheless, the rate of any colostomy at initial surgery in the intervention arm was slightly lower for both cases with a demonstrator (22\%) and those without a demonstrator $(31 \%)$, although the difference was not significant $(p=0.06)$.

\section{Interpretation}

Voluntary participation of surgeons in our trial was high (91\%). Perhaps the most challenging part of the intervention was intraoperative demonstrations; yet $70 \%$ of the surgeons in the intervention arm invited an operative demonstrator, and these surgeons provided care to $86 \%$ of the patients in the intervention group. We expected our resource-intense strategy to improve patient outcomes. In a qualitative study, surgeons in the intervention arm uniformly reported that the QIRC strategy had led to improvements in the quality of their rectal surgery. ${ }^{24}$ As well, a pilot study using before-after analyses showed a marked improvement in patient outcomes when surgery was provided by surgeons who participated in the QIRC strategy, but not among nonparticipating surgeons. ${ }^{16}$ However, in our current trial, use of the QIRC strategy did not lower hospital rates of permanent colostomy and local recurrence of cancer. Of interest, in the 
intervention arm, results were similar among surgeons when we grouped them by different practice volumes or degrees of participation in the components of the QIRC strategy.

Our findings also suggest that care in the intervention arm — and by extension care in the control arm — was suboptimal. In an exploratory analysis in the intervention arm, the median distance from the tumour to the anal verge was closer among patients whose surgeon worked with an operative demonstrator than among those whose surgeon did not have an intraoperative demonstration $(6 \mathrm{~cm} \mathrm{v.} 10 \mathrm{~cm})$. Despite this, there was a lower colostomy rate at initial surgery and at final surgery (about 5\% lower) in the group that had a demonstration, although these differences did not reach statistical significance. As well, the rates of permanent colostomy in the intervention (39\%) and control arms (41\%) were much higher than those seen in units that self-identify as practising total mesorectal excision. ${ }^{3-5}$ Rates of local recurrence at $6 \%$, although encouraging in comparison to results from other jurisdictions, likely could have been even lower. In a multicentre randomized trial by Sebag-Montefiore and colleagues, "good" mesorectal excision surgery and preoperative radiation led to a rate of local recurrence of only $1 \%$.

\section{Limitations}

Our study has limitations. First, we could not measure the surgeons' baseline or intra-trial quality of surgery. There are no validated tools that can determine whether a surgeon is providing high-quality total mesorectal excision surgery. Second, participating surgeons were not asked to do specific followup tests for local recurrence; thus, some local recurrences may have been missed. However, patient symptoms related to a

Table 3: Clustered survival analysis to assess factors associated with time to local recurrence of tumour*

\begin{tabular}{|c|c|}
\hline Factor & $\mathrm{HR}(95 \% \mathrm{Cl})$ \\
\hline Intervention arm (v. control arm) & $0.96(0.61-1.52)$ \\
\hline Sex, male (v. female) & $1.01(0.60-1.70)$ \\
\hline Age, per 10-year increase & $1.01(0.75-1.37)$ \\
\hline \multicolumn{2}{|l|}{ Comorbidities (v. none) } \\
\hline 1 & $0.84(0.48-1.45)$ \\
\hline$\geq 2$ & $0.91(0.39-2.12)$ \\
\hline Tumour size, per $1-\mathrm{cm}$ increase & $1.10(1.00-1.20)$ \\
\hline \multicolumn{2}{|l|}{ TNM stage (v. stage 1 ) } \\
\hline 2 & $1.30(0.54-3.12)$ \\
\hline 3 & $1.36(0.57-3.25)$ \\
\hline 4 & $1.47(0.49-4.36)$ \\
\hline \multicolumn{2}{|l|}{ Histologic grade (v. poorly differentiated) } \\
\hline Moderately differentiated & $1.10(0.47-2.58)$ \\
\hline Well differentiated & $0.84(0.30-2.37)$ \\
\hline Vascular, lymphatic or neural invasion (v. none) & $0.86(0.48-1.57)$ \\
\hline $\begin{array}{l}\text { Positive circumferential radial margint } \\
\text { (v. negative margin) }\end{array}$ & $2.02(0.70-5.83)$ \\
\hline Any use of radiation (v. no use) & $1.38(0.82-2.33)$ \\
\hline Low anterior resection (v. permanent colostomy) & $0.82(0.56-1.19)$ \\
\hline
\end{tabular}

Note: $\mathrm{Cl}=$ confidence interval, $\mathrm{HR}$ = hazard ratio.

* Model considered clustering of data at hospital level.

†Positive circumferential radial margin $=$ distance $\leq 1 \mathrm{~mm}$. local recurrence rapidly result in hospital-based tests or a referral to a regional cancer centre for assessment by a radiation or medical oncologist. Third, with a median follow-up of 3.6 years, local recurrence will likely occur in a small number of patients after completion of the trial. But it is unlikely that the number will skew to one of the trial arms. Finally, our results may not be generalizable. But the participating surgeons in our trial provide care for about $25 \%$ of all patients with rectal cancer in Ontario. ${ }^{25}$ Thus, our findings probably apply to other surgical settings in North America.

\section{Conclusion}

It is a paradox that the quality of medical care improves over time, and can even do so very rapidly, ${ }^{26}$ yet explicit efforts to accelerate such improvement or to close identified gaps in quality are often met with frustration. ${ }^{27}$ Although the high participation rate by surgeons in our study runs counter to the assumption that clinicians are reluctant to consider changes in practice, our negative trial results add to a growing number of studies showing a relative inability to quickly close quality gaps. These findings should encourage the design and appropriate evaluation of new quality-improvement methods..$^{28,29}$

This article has been peer reviewed.

Competing interests: None declared.

Contributors: Marko Simunovic, Angela Coates, Charles Goldsmith, Lehana Thabane, Andrew Smith, Robin McLeod, Franco DeNardi, Timothy Whelan and Mark Levine contributed to the study concept and design. Marko Simunovic, Angela Coates, Charles Goldsmith, Lehana Thabane and Dana Reeson acquired the data. Data analysis and interpretation was done by Marko Simunovic, Angela Coates, Charles Goldsmith, Lehana Thabane, Robin McLeod, Franco DeNardi and Mark Levine. Marko Simunovic, Angela Coates, Charles Goldsmith, Lehana Thabane, Andrew Smith, Robin McLeod, Franco DeNardi, Timothy Whelan and Mark Levine drafted the manuscript, and all of the authors revised the manuscript for important intellectual content. Statistical analysis was done by Marko Simunovic, Angela Coates, Charles Goldsmith and Lehana Thabane. Marko Simunovic, Angela Coates and Mark Levine obtained funding for the study. Marko Simunovic, Angela Coates and Dana Reeson gave administrative, technical and material support, and the study was supervised by Marko Simunovic and Mark Levine. All of the authors approved the final version of the manuscript. Marko Simunovic, Charles Goldsmith and Lehana Thabane had full access to all of the study data and take responsibility for the integrity of the data and the accuracy of the analysis.

Acknowledgements: The authors gratefully acknowledge the expertise and time that the intraoperative demonstrators provided during the course of the trial. The authors thank Eddy Rempel for design and maintenance of the database and for statistical guidance, Laura Childerhose for acquisition of data and administrative support, and Emmy Cheng and Gary Foster for statistical analyses and interpretation.

The authors also thank the generous support of the surgeons, administrative staff and departments at the participating hospitals (Credit Valley Hospital, Humber River Regional Hospital - Mississauga Site, Joseph Brant Memorial Hospital, Niagara Health System - Niagara Falls Site, Niagara Health System St. Catharines Site, North Bay General Hospital, North York General Hospital, Rouge Valley Health System - Centenary Site, St. Joseph's Health Centre Sudbury Site, The Scarborough Hospital - Grace Site, Southlake Regional Hospital, Thunder Bay Regional Health Sciences Centre, Toronto East General Hospital, Trillium Health Centre - Mississauga Site, and the William Osler Hospital - Brampton and Etobicoke Sites).

Funding: The trial was funded by a grant from the Canadian Institutes of Health Research (grant no. MCT-50013).

\section{REFERENCES}

1. Soreide O, Norstein J. Local recurrence after operative treatment of rectal carcinoma: a strategy for change. J Am Coll Surg 1997;184:84-92. 
2. Havenga K, Enker WE, DeRuiter MC, et al. Anatomical basis of total mesorecta excision and preservation of the pelvic autonomic nerves. In: Soreide O, Norstein J, editors. Rectal Cancer Surgery. Optimisation, standardisation, documentation. New York (NY): Springer-Verlag; 1997. p. 134-42.

3. Bernstein MA, Amarnath B, Weiss EG, et al. Total mesorectal excision without adjuvant therapy for local control of rectal cancer: a North American experience. Tech Coloproctol 1998;2:11-5.

4. Arenas RB, Fichera A, Mhoon D, et al. Total mesenteric excision in the surgica treatment of rectal cancer: a prospective study. Arch Surg 1998;133:608-12.

5. Heald RJ, Moran BJ, Ryall RDH, et al. The Basingstoke experience of total mesorectal excision. Arch Surg 1998;133:894-9.

6. Sebag-Montefiore D, Stephens RJ, Steele R, et al. Preoperative radiotherapy versus selective postoperative chemoradiotherapy in patients with rectal cancer (MRC CR07 and NCIC-CTG C016): a multicentre, randomised trial. Lancet 2009;373 811-20.

7. Paszat LF, Brundage $\mathrm{M}$, Groome $\mathrm{P}$, et al. A population-based study of rectal cancer permanent colostomy as an outcome. Int J Radiat Oncol Biol Phys 1999;45:1185-91.

8. Porter GA, Soskolne CL, Yakimets WW, et al. Surgeon-related factors and outcome in rectal cancer. Ann Surg 1998;227:157-67.

9. Thomson O'Brien MA, Freemantle N, Oxman AD, et al. Continuing education meetings and workshops: effects on professional practice and health care outcomes [review]. Cochrane Database Syst Rev 2001;(2):CD003030.

10. Jamtvedt G, Young JM, Kristoffersen DT, et al. Audit and feedback: effects on professional practice and health care outcomes [review]. Cochrane Database Syst Rev 2003;(3):CD000259.

11. Thomson O'Brien MA, Oxman AD, Haynes RB, et al. Local opinion leaders: effects on professional practice and health care outcomes [review]. Cochrane Database Syst Rev 2000;(2):CD000125.

12. Berwick DM. Controlling variation in health care: a consultation from Walter Shewhart. Med Care 1991;29:1212-25.

13. Kritchevsky SB, Simmons BP. Continuous quality improvement. Concepts and applications for physician care. JAMA 1991;266:1817-23.

14. Douglas P, Asimus M, Swan J, et al. Prevention of orthopaedic wound infections: quality improvement project. J Qual Clin Pract 2001;21:149-53.

15. Ferguson TB, Peterson ED, Coombs LP, et al. Use of continuous quality improvement to increase use of process measures in patients undergoing coronary artery bypass graft surgery. JAMA 2003;290:49-56.

16. Simunovic MI, Paterson CA, Coates AJ, et al. Pilot study of the Quality Initiative in Rectal Cancer strategy. Dis Colon Rectum 2004;47:1594-8.

17. Simunovic M, Goldsmith $\mathrm{CH}$, Thabane L, et al. The Quality Initiative in Rectal
Cancer (QIRC) trial: study protocol of a cluster randomized controlled trial in surgery. BMC Surg 2008;8:4

18. Hiss RG, MacDonald R, Davis WK. Identification of physician educational influentials (EI's) in small community hospitals. Res Med Educ 1978;17:283-8.

19. Donner A, Klar N. Methods for comparing event rates in intervention studies when the unit of allocation is a cluster. Am J Epidemiol 1994;140:279-89.

20. Barnard J, Meng XL. Applications of multiple imputation in medical studies: from AIDS to NHANES. Stat Methods Med Res 1999;8:17-36.

21. Diggle PJ, Heagerty P, Liang K, et al. Analysis of longitudinal data. 2nd ed. Oxford (UK): Oxford University Press; 2002.

22. Ying G, Liu C. Statistical analysis of clustered data using SAS System. Proceedings of the North East SAS Users Group (NESUG) Conference; 2006 Sept. 17-20; Philadelphia.

23. Canadian Institutes of Health Research, Natural Sciences and Engineering Research Council of Canada, Social Sciences and Humanities Research Council of Canada. Tri-council policy statement: ethical conduct for research involving humans. 1998 (with 2000, 2002 and 2005 amendments). Available: www.pre.ethics.gc.ca/english /policystatement/introduction.cfm (accessed 2009 Sept. 24).

24. Wright FC, Simunovic M, Coates A, et al. Quality initiative in rectal cancer strategy: a qualitative study of participating surgeons. J Am Coll Surg 2006;203:795-802.

25. Neshi R, Baxter N, Kennedy E, et al. Surgery for colorectal cancer. In: Urbach DR, Simunovic M, Schultz SE, editors. Cancer surgery in Ontario: ICES Atlas. Toronto (ON): Institute for Clinical Evaluative Sciences; 2008. Available: www.ices.on.ca /webpage.cfm?site_id=1\&org_id=67\&morg_id=0\&gsec_id=0\&item_id=5281\&type $=$ atlas (accessed 2009 Sept. 24).

26. Simunovic M, Baxter N. Knowledge translation research: a review and new concepts from a surgical case-study. Surgery 2009;145:639-44.

27. Simunovic M, Baxter NN. Lymph node counts in colon cancer surgery: lessons for users of quality indicators. JAMA 2007;298:2194-5.

28. Graham ID, Logan J, Harrison MB, et al. Lost in knowledge translation: Time for a map? J Contin Educ Health Prof 2006;26:13-24.

29. Eccles M, Grimshaw J, Walker A, et al. Changing the behaviour of healthcare professionals: the use of theory in promoting the uptake of research findings. $J$ Clin Epidemiol 2005;58:107-12.

Correspondence to: Dr. Marko Simunovic, Juravinski Cancer Centre, 699 Concession St., Hamilton ON L8V 5C2;

marko.simunovic@jcc.hhsc.ca

\section{PrAGCUPRIL ${ }^{\circledR}$ and ${ }^{\mathrm{P} A G C U R E T I C}{ }^{\circledR}$}

Still fighting

hypertensiont

$\checkmark$ Powerful BP-lowering ${ }^{1}$

$\checkmark$ ACCUPRIL's 24-hour BP control ${ }^{1}$

$\checkmark$ The flexibility of seven dosage strengths with ACCUPRIL and ACCURETIC1,2

\section{$\checkmark$ Al dosages at a single flat price ${ }^{3 \dagger}$}

† Price does not include pharmacy professional fees. Please refer to Product Monographs for complete dosing information.

P

(quinapril hydrochloride)

TAKE A FORWARD STEP
$\mathbf{P}$

POWER OF COMBINED CONTROL

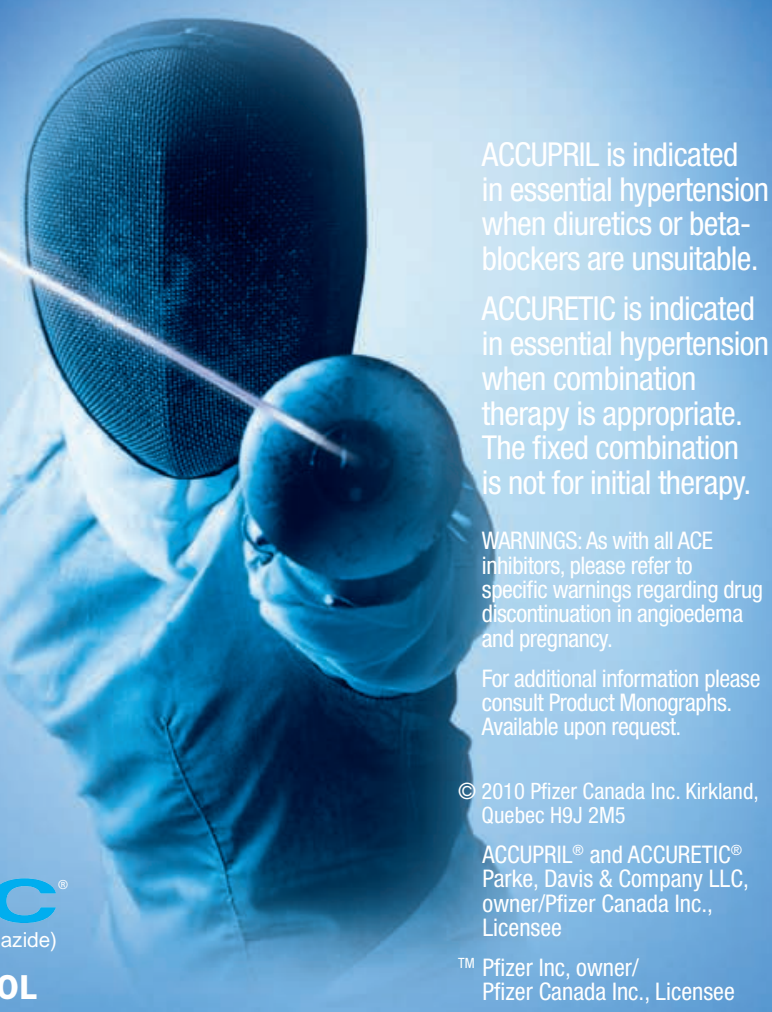

